\title{
Modern Problems of Increasing Coal Mines Power Supply Efficiency
}

\author{
Fedor Nepsha ${ }^{1,}$, Roman Belyaevsky ${ }^{1}$, Vladimir Efremenko ${ }^{1}$, and Kirill Varnavskiy ${ }^{2}$ \\ ${ }^{1}$ T.F. Gorbachev Kuzbass State Technical University, 650000, 28 Vesennyaya St., Kemerovo, Russia \\ ${ }^{2}$ Shandong University of Science and Technology, Qingdao, PR China
}

\begin{abstract}
In this article, the authors consider the main problems of increasing the efficiency of coal mines electrical power system (EPS). The identified problems are divided into two groups: problems that can be solved at the design stage and problems that can be solved at the operation stage. Within each group, the authors consider various problems and propose possible solutions. It is noted that as a result of the solution of formulated problems it is possible to form the problem of developing an intelligent coal mines EPS. To solve this problem it is necessary to use modern technologies such as IoT (Internet of Things) and BIG DATA. In prospective it will allow to create a unified cyber-physical system uniting the virtual and real worlds within the framework of the coal mining technological process and ensuring the rational management of the coal mine EPS by the criterion of minimizing the energy consumption for extracting one ton of coal. As a conclusion, the authors note the necessity of solving the formulated problems for the implementation of the "Industry 4.0 " concept, which has great importance for the Russian coal industry.
\end{abstract}

\section{Introduction}

The development of modern coal mines characterized by increasing of excavation and transport machines power per unit ratio, by increasing in the load on the coal-faces and the intensification of coal mining processes. It requires the creation of higher-quality electrical power supply systems and the increasing in the efficiency of used underground electrical equipment. The Russian coal industry has great potential for energy saving. The actuality of organizational and technical measures development for energy saving on coal mines is confirmed by the Approval of the Government of the Russian Federation No. 1099-r dated 21 June 2014 "Long-term development plan of the coal industry for the period up to 2030". This program provides for reducing active energy consumption and energy losses in all elements of coal mine EPS. Its implementation should reduce the electricity component of the russian coal price and increase its competitiveness in the world market. To achieve these goals, it is necessary to develop scientifically based approaches and solutions to improve the coal mine EPS efficiency.

\footnotetext{
*Corresponding author: nepshafs@gmail.com
} 
According to [1], the efficiency of electrical power supply $E$ is determined by the completeness of EPS required performance achievement (reliability, electric power quality, safety, and EPS elements efficiency):

$$
E=f\left(t_{f}, t_{f, r .}, U_{j}^{*}, t_{r}, \Delta_{\Delta w}^{*}\right),
$$

Its satisfactory values are obtained under the conditions:

$$
\begin{aligned}
& P_{e l}\left[\left(t_{f}, t_{f . r .}\right) ;\left(t_{\text {out.el. }} \leq t_{r . e l .}\right)\right] \geq P_{\text {norm.el }}, \\
& U_{j}^{*} \geq U_{j n o r m}^{*} ; t_{r} \leq t_{\text {a.d. }} ; \Delta_{\Delta w}^{*} \rightarrow \min ,
\end{aligned}
$$

where $t_{f}, t_{\text {r.t. }}-$ respectively, time between failures and the average EPS recovery time, hr; $U_{j}^{*}, U_{\text {jnorm }}^{*}$ - the relative voltage value at the mining machine motor terminals when it operates in the $j$ - mode and its normative value; $t_{r}$ - the time for removing the voltage from broken cable segment or electrical equipment, $\mathrm{s}, t_{\text {a.d. }}$ - EPS accident development time, $\mathrm{s}$, $\Delta^{*}{ }_{\Delta \mathrm{w}}$ - the relative value of reducing the coal mine specific power consumption when implementing energy-saving measures (including increasing the production intensity); $P_{e l}\left[\left(t_{f}, t_{f . r .}\right)\right], P_{\text {norm.el }}$ - accordingly, the probability that the system will perform the power supply of output targets - transfer to the consumer (technological systems of the extraction area) the planned amount of electricity and its standard value; $t_{\text {out.el }} \leq t_{\text {r.el. }}-$ respectively, the total time of technological system forced outage of the extraction area in case of EPS elements failure and its temporary redundancy to restore normal power supply, hr.

Formulae (1) and (2) show that the objective of the EPS efficiency improvement is multi-criteria and includes many problems. The authors consider that in this case, it is expedient to consider the problem of the EPS efficiency improvement from the position of reducing the personnel number and moving towards the creation of an "unmanned coal mine".

In connection with the foregoing, the classification of the main problems of coal mines EPSs efficiency improvement represent the scientific interest.

This article has the following structure - the second section considers the main problems of coal mines efficiency improving. Also it discusses the complex problem of creating an intelligent coal mine EPS and the associated perspective technologies. Finally, the third section contains the conclusion of the article.

\section{Results and discussion}

The authors analyzed possible ways to improve the coal mines EPSs efficiency. Based on the results of the analysis, the proposed scientific and technical problems to improve the EPS efficiency are formed and represented on Fig. 1.

The problems of improving the EPS coal mines energy efficiency are divided into two main groups: 1) problems that can be solved at the design stage; 2) problems that can be solved at the operation stage.

The problems that can be solved at the design stage. Its solution is especially important because it allows to realize the energy saving potential at the design stage. Therefore, the total economic benefit is maximum. These problems include the following:

1. Reactive power compensation and selection of harmonics filter parameters. At present, on the electrical equipment market, there are explosion-proof mining capacitor units (UKRV) [2]. UKRVs have a significant size (3 meters $20 \mathrm{~cm}$ length for single-step units) and weight (3900 kg for single-step units). In addition, multi-step UKRVs have bigger size and weight that's why it becomes hard to place it at the extraction area. Due to the abruptly variable load, it is of great interest to use other devices for reactive power compensation, 
for example, static VAR compensator, dynamic sag correctors (DySC), static synchronous compensators (STATCOM) [3].

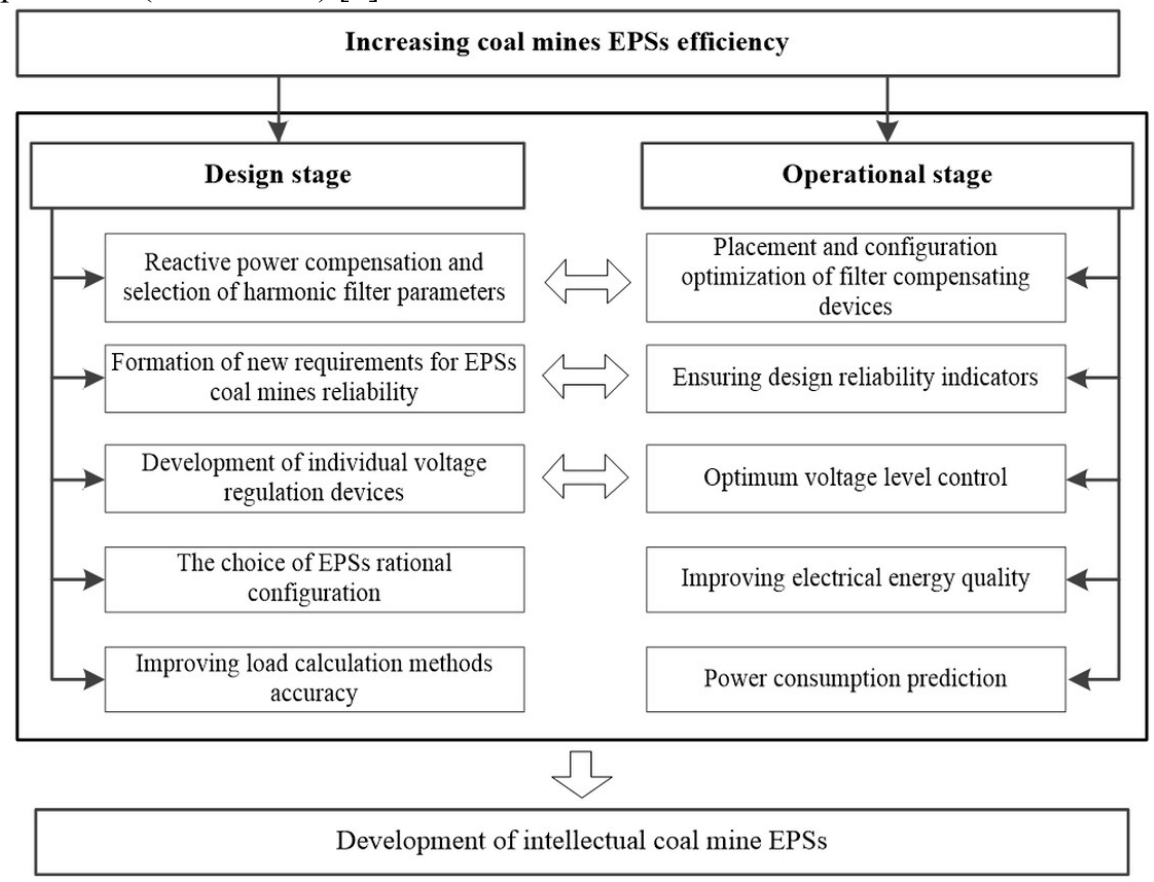

Fig. 1. The main objectives of increasing the coal mines EPSs efficiency

The above-mentoined devices have high operation speed (switching time from 4 to 500 $\mathrm{ms}$ ) compared with static capacitors batteries (switching time from $3 \mathrm{~s}$ to $2 \mathrm{~min}$ ).

It should be noted that there is no single approach to the selection of reactive power compensation devices in the EPS of coal mine. The approach created by UKRM manufacturing enterprises is not technically justified because it doesn't take into account the dynamic nature of the coal mine load and it is aimed at providing the desired tg $\varphi$ while its value remains in question.

The authors note [4] that when determining the reactive power compensation device configuration it is necessary to take into account the effect of voltage on reactive power and the additional increase in active power losses due to the presence of higher harmonics.

In addition, in the EPS design documentation of the extraction area, there are no sections "Reactive power compensation" and "Checking the chosen reactive power compensation device for possible overload by high harmonic currents and the absence of conditions for the occurrence of resonant phenomena". Therefore, taking into account the development of technology, the existing design solutions are not rational.

2. Formation of new requirements for the EPS coal mines reliability. Improvement of coal mines EPSs reliability has great importance for Russian energy security (including Kemerovo region). Currently, there is a growth tendency [5] of emergency blackouts. In order to reduce the emergency blackoutsnumber, it's required to revise regulatory documents to develop certain technical solutions to improve the internal and external EPS reliability. The authors consider that it's promising to use the structure orderliness assessment method proposed in [6] for assessing the effectiveness of measures to improve the coal mines EPSs reliability at the design stage.

3. Development of individual voltage regulation devices. Taking into account the growth of power per unit ratio in the extraction areas of coal mines, it becomes expedient to consider 
individual voltage regulation devices, such as booster transformers and on-load tap changer. The last one can be installed on mobile local underground substations.

The importance of this direction is due to the fact that individual voltage regulation can fully realize the potential of rational voltage regulation and increase the motor load stability during system blackouts associated with a voltage decrease in the power grid.

4. The choice of EPS rational configuration. Currently, during design process of coal mines the optimization of electrical equipment placement is not provided.. Its placement is determined only by technology and is selected "by sensations". In fact, the existing structure of the coal mines EPSs is not scientifically and technically justified. In that case, it's expedient to develop a computer-aided design (CAD) program for coal mines EPSs.

5. Improving load calculation accuracy. Currently, for the calculation of electrical loads in the coal mines EPSs, the designers use the demand coefficient method, which was introduced in 1891 by R. Crompton. Estimated demand factors were obtained in the 1990s. Since this period, the equipment energy intensity has significantly increased. In this connection, it is necessary to revise current load calculation methods and to develop load calculation methods based on coal mine simulation modeling. In this direction, the authors note the work [7] that proposes a simulation model method for determining the power of electrical consumers taking into account the mining and geological conditions and technological interrelations.

It is important to note that in order to solve the above mentioned problems, it is necessary to carry out comprehensive scientific and technical research in collaboration with the owners of the coal mines.

Problems that can be solved at the operation stage. The solution of such problems is relevant for existing coal mines. In such a case it is possible to supplement the EPS structure without a thorough change.

1. Placement and configuration optimization of filter compensating devices. Analysis of the use of reactive power compensation devices shows that they are installed on the buses of the main step-down substations, and they are controlled only by the criterion of ensuring a given $\operatorname{tg} \varphi$. Thus, the potential for energy saving is not fully realized. However, as noted above, the UKRM appeared which can be placed near electrical consumers. In this regard, it is required to develop a methodology for optimizing the UKRM placement and configuration at coal mines.

2. Ensuring design reliability indicators. During the coal mines operation activity, there is a gradual deterioration of equipment, therefore, periodic monitoring of its condition is necessary. It is also advisable to create a system for diagnosting of electrical equipment, which allows to minimize the presence of personnel underground. At the same time, to reach this aim it's necessary to create the innovation control structure of coal mine extraction area as shown in [8].

3. Optimal voltage level control. As noted in [2], the optimal voltage level in coal mines EPSs is not ensured. Taking into account the appearance of explosion-proof mining capacitor units, it becomes expedient to develop a system of active and adaptive voltage level control that could provide a rational voltage level at the terminals of the electrical consumers taking into account the features of the technological process.

4. Improving electrical energy quality. Analyzes of the electrical energy quality indicators in coal mines show that harmonic components coefficients are not correspondto the standard values. In [9] it is proposed to use electrical energy control devices in the conditions of coal mines EPSs.

5. Power consumption prediction. The cost for electricity consumption at a coal mine can be reduced by increasing the accuracy of forecasting the electrical consumers operation modes. However, energy consumption forecasting issues remain underdeveloped for coal mines. This is largely due to the abruptly variable nature of the coal mines load. In 
particular, in this direction, it is necessary to note the paper [10] that propose the use of artificial neural network and algorithms to minimize the electricity cost. Its principles can be adapted for coal mines.

Ultimately, the solution of the above mentoined problems will lead to the formation of a new problem, which is necessary for the innovative development of the Russian coal industry. Such a problem is the development of intelligent coal mine EPS. The general concept of intellectual EPS of mineral resources sector enterprises was proposed in [11]. It is noted that the intelligent EPS should provide management of all types of electricity generation, control of any types of consumers, change of parameters and topology of the network under current conditions, voltage regulation to ensure minimum losses, integrated energy efficiency accounting and all-mode control with full-scale information support.

The authors of the article consider that while solving this problem it is necessary to use promising technologies such as IoT "Internet of Things" and BIG DATA. There are a small number of publications devoted to the use of these technologies in the coal mines conditions. For example, article [12] provides a general overview of the possible use of IoT technology to improve the performance, safety, and efficiency of coal mining enterprises. It is noted that the architecture of the Internet of Things should have a layered structure. The article [13] discusses the use of IoT technology for the predictive control of the mining equipment operation state. At the same time, it is supposed to use IoT technology to predict the state of equipment, reduce operating costs and time spent by staff underground. The article [14] discusses key technologies for automating the process of coal mining based on IoT. In particular, applications of IoT are considered to reduce the number of accidents through the creation of a monitoring system and equipment management based on the existing industrial Internet system and sensors, including sensors connected to a wireless communication system (Wi-Fi). It is noted that the automation of coal mines based on the "Internet of Things" technology should provide the cyber-physical system of the coal mine with the following functions: 1) ensuring interconnected control of the technological process to ensure production safety; 2) tracking of personnel; 3) early warning of mine disaster; 4) ensuring the safe evacuation of personnel and disaster relief [15]; 5) realization of coal mine informational management $[18,19]$.

Notwithstanding the above, there are no publications containing specific solutions to local problems of IoT implementation in coal mining enterprises.

Within the framework of the concept "Industry 4.0" [17], EPS and technological scheme of coal mine extraction should be presented in the form of a unified cyber-physical system capable of adaptation while coal mine conditions change and emergency situations arise. In this case, the main criterion for the management efficiency of coal mines EPSs should be the minimization of the production price of coal per ton, which can be easily realized by creating feedback between the production line and the coal mine EPS. In this case, it would be advisable to consider the cyber-physical system in the form of a multilevel model that provides both selective and generalized control of technological processes of production and power supply.

\section{Conclusions}

1. The authors grouped the main scientific and technical problems. Its solution is necessary for increasing the coal mines EPSs efficiency.

2. The presented problems were divided into two main groups. The authors noted that scientific and technical problems at the design stage represent the great interest. Their solution allows to reach a maximum of technical-and-economic indices. 
3. Currently, in the coal mines conditions, the problems of reactive power compensation and power consumption prediction practically are not solved. It does not allow to realize the power saving potential.

\section{References}

1. Yu. Minovsky, V. Fashilenko, Moscow mining University bulletin, 10, (2012)

2. F. Nepsha, V. Efremenko, E3S Web Conf., 41, 03013 (2018)

3. E. Tretyakov, N. Malysheva, A. Krause, Journal of Transsib Railway Studies, 4, 10 (2010)

4. R. Belyaevsky, V. Efremenko, F. Nepsha, Proceedings of the 9th China-Russia Symposium, 268, 10 (2018)

5. A. Savinkin, Coal of Kuzbass, 3, 9 (2015)

6. K. Varnavskiy, V. Matveyev, Industrial Power Engineering, 4, 6 (2016)

7. Yu. Razumnyy, A. Rukhlov A. B., GIAB, 6, 55 (2004)

8. K. Kopilov, S. Kubrin, S. Reshetnyak, Coal, 10, 78 (2018)

9. S. Kubrin, S. Reshetnyak, Mining informational and analytical bulletin, 11, 110 (2014)

10. I. Babanova, B. Abramovich, S. Petrov, Industrial Power Engineering, 12, 25(2017)

11. B. Abramovich, Yu. Sychev, D. Ustinov, Energy Academy, 3, 41 (2011)

12. A. Sharma, A. Sharma, S. Gupta, IJEECS, 6, 2 (2017)

13. L. Dong, R. Mingyue, M. Guoying, 13th Global Congress on Manufacturing and Management, Procedia Engineering, 174 (2017)

14. X. Zhang, X. Yang, ICSSR, 12, 100 (2014)

15. Z. Ke-fei, Z. Ming, W. Yun-jia, F. Er-jiang, W. Cartwright, Procedia Earth and Planetary Science, 1, 01012 (2009)

16. V. Efremenko, R. Belyaevsky, Taishan Academic Forum - Project on Mine Disaster Prevention and Control, 190 (2014)

17. Yu. Plakitkin, L. Plakitkina, Coal, 10, 14 (2017)

18. J. Wang, Z. Huang. Engineering, 3, 92 (2017)

19. Jian-guo Li, Kai Zhan, Engineering, 4, 130 (2018) 